\title{
Verificação de Interesse para a Implantação de uma Cafeteria na Cidade de Brejo Santo-CE
}

Leticia Ricarte Teles $^{1}$; Thalia Lourdes Ferreira ${ }^{2}$; Manoel Leal Costa Netto ${ }^{3}$; Alyne Leite de Oliveira ${ }^{4}$; Tharsis Cidália de Sá Barreto Diaz Alencar ${ }^{5}$

\begin{abstract}
Resumo: A Economia Criativa impulsiona o empreendedorismo em setores menos explorados, criando um ambiente menos competitivo, onde o empreendedor se destaca somente pelo seu diferencial. Este trabalho tem como objetivo verificar o interesse da população da cidade de Brejo Santo- CE em frequentar e consumir produtos em cafeteria com enfoque gourmet. Para tanto, esta pesquisa foi de natureza básica, quantitativa, através da aplicação de 130 questionários junto à população. Pode observar-se que existe aceitação por parte da população da cidade de Brejo Santo para a implantação de uma cafeteria, tendo como principais fatores de aceitação o ambiente e a qualidade do produto.
\end{abstract}

Palavras Chave: Cafeteria. Gourmet. Empreendedorismo.Economia Criativa.

\section{Verification of Interest for the Implementation of a Cafeteria in the City of Brejo Santo, State of Ceará}

\begin{abstract}
The Creative Economy boosts entrepreneurship in less exploited sectors, creating a less competitive environment, where the entrepreneur stands out only for its differential. This work aims to verify the interest of the population of Brejo Santocity,state of Ceará, in attending and consuming products in coffee shopwith gourmet approach. Therefore, this research was of a basic, quantitative, through the application of 130 questionnaires to the population. It can be observed that there is acceptance by th epopulationof Brejo Santo City, for the implantation of coffee shop, having as main factors of acceptance the environment and the quality of the product.
\end{abstract}

Keywords: Coffee Shop. Gourmet. Entrepreneurship.CreativeEconomy.

\section{Introdução}

O empreendedorismo é fator primordial para o crescimento de um país. Segundo a Revista Isto é (2018), até o ano de 2017, o número de empreendedores brasileiros que tem participação no mercado empresarial, com faixa etária entre 18 a 34 anos aumentou de 50\% para 57\%, sendo 49,3 milhões de jovens brasileiros empreendedores. Analisando esse contexto, 59,4\% dessa população empreendem por

\footnotetext{
${ }^{1}$ Graduando do curso de Administração do Centro Universitário Doutor Leão Sampaio Unileão- email: leticiaricarte0@gmail.com;

${ }^{2}$ Graduando do curso de Administração do Centro Universitário Doutor Leão Sampaio Unileão- email: thalia.ce@ hotmail.com;

${ }^{3}$ Mestrado em Engenharia Agrícola pela Universidade Federal Rural de Pernambuco. Professor da Faculdade de Ciências Aplicadas Leão Sampaio, Brasil;

${ }^{4}$ Professor do co orientador do Centro Universitário Doutor Leão Sampaio. Especialista em MBA Logística Empresarial;

${ }^{5}$ Professor do co orientador do Centro Universitário Doutor Leão Sampaio. Especialista em Engenharia da Produção.
} 
oportunidade, ao contrário de 55,8\% que empreendem apenas por necessidade, percentual considerado alto em relação a dados de 2014.

Vale ressaltar, dentre esse percentual, que 20,7\% são mulheres empreendedoras, quebrando assim paradigmas e preconceitos existentes na sociedade, além de expandir cada vez mais o mercado empresarial (REVISTA ÉPOCA NEGÓCIOS, 2018).

No cenário executivo um novo formato vem surgindo no segmento mercadológico, a Economia criativa é o conjunto de negócios baseados no capital intelectual e cultural e na criatividade que gera valor econômico (SEBRAE, 2018).

Assim com o surgimento da nova economia, e diante das novas tendências alimentares, aumenta a busca por alimentos caseiros, naturais e regionalistas atentando-se pelo teor de sustentabilidade desses produtos. Com a expansão mercadológica a procura por refeições fora do lar também está em crescimento, os principais setores afetados positivamente foram os da área gourmet e fitness, buscando qualidade de vida aliada ao bem-estar (SEBRAE, 2017)

Segundo a Euromonitor (2017) o setor de café está em crescimento, com grande demanda para consumo, o mercado em 2017 se manteve em crescimento com 3\%, e mesmo com a inconstância econômica as pessoas continuam consumindo, a previsão para 2021 é que o consumo aumente para 3,6\%.Nos centros urbanos a variedade de estabelecimentos e a diferenciação por meio do posicionamento é uma das ferramentas usadas para atrair clientes. Por ser próximo ao ambiente de trabalho os proprietários buscam associar os estabelecimentos a um local que favoreça o convívio profissional.

Diante desse cenário o principal objetivo desse trabalho é verificar o interesse da população da cidade de Brejo Santo- CE em frequentar e consumir produtos em cafeteria com enfoque gourmet, onde se busca identificar os perfis dos consumidores de cafés e afins, identificando o que impulsiona a aderir a ambientes gourmetizados e promover a discussão sobre as novas tendências de mercado.

\section{Empreendedorismo}

$\mathrm{O}$ início do século XX foi um período de grande inquietação, onde surgiram várias ideias, processos e produtos que passam a satisfazer as necessidades dos indivíduos. Vale ressaltar que não só teve o intuito de satisfazer as necessidades, mais modificar e inovar o mercado, tendo como perspectiva um novo olhar sobre os problemas inseridos no ambiente (DORNELAS, 2016).

Empreendedorismo é pautado por reflexões feitas a partir de certo conceito ou prática de um determinado segmento, seja ele inteiramente novo ou já existente. Mas claramente são percepções nas 
quais o gestor indaga-se da sua pró-atividade, ou seja, melhorias em negócios já formados ou criação de novos segmentos de mercado (CHIAVENATO, 2012).

Empreendedor é aquele que "desorganiza” todo o cenário econômico que já existe, introduzindo no mercado novos produtos e serviços, criando diferentes organizações e explorando os diversos setores com a criação de novos materiais e recursos. Portanto pode ser definido também como ligações ente indivíduos e processos, que juntos convertem ideias em oportunidades (DORNELAS, 2014, 2016). Desta forma, observa-se que há uma transformação das ideias em oportunidades ou o desenvolvimento de ideias para suprir oportunidades.

A desorganização do ambiente para uma organização que gere valor ao empreendedor deve ser feita de forma pragmática e acessível não somente ao consumidor, como também à sociedade em geral, como diz Mendes (2017), ao afirmar que para ser empreendedor não é apenas desorganizar o contexto econômico com novos produtos e serviços, mas acrescenta também que tem que haver capacidade de transformar tudo em maneiras mais simples e acessíveis para as pessoas que rodeiam.

O empreendedor é aquele indivíduo que assume risco e implanta uma nova forma de mercado, explorando novos hábitos, habilidades, valores e o impacto que essa nova patente irá ter para a sociedade. (SALIM e SILVA, 2010; CHIAVENATO, 2012). Não significa dizer que empreendedor é somente o "dono de uma empresa", mas o indivíduo que assume riscos por mudanças organizacionais com a finalidade de alavancar os negócios, caracterizando-se, desse modo como intraempreendedores, ou seja, intraempreendedorismo é voltado para a capacitação dos colaboradores, com o propósito de aumentar os negócios e a lucratividade (TAJRA, 2014). Ainda que no contexto descrito, o que prevalece é a inovação e contribuição dentro do próprio ambiente de trabalho (MENDES, 2017)

Complementando o que foi citado, Hisrich; Peters; Shepherd (2014) diz que empreendedores podem ser descritos ainda como aqueles indivíduos que tem outras concepções das coisas, diferentemente do pensamento comum das demais pessoas, tendo maior facilidade de tomar decisões em ambientes altamente desfavoráveis e críticos, onde o emocional é o maior investimento a ser feito, ou seja, é uma série de procedimentos psicológicos onde conclui-se certos indícios de oportunidades merecem ser investidos ou descartados.

Conforme Dornelas (2008), estudos mostram que os empreendedores que apresentam maiores sucessos, tem as seguintes características:

316 Id on Line Rev. Mult. Psic. V.12, N. 42, Supl. 1, p. 314-334, 2018 - ISSN 1981-1179 Edição eletrônica em http://idonline.emnuvens.com.brlid 
Quadro 1: Características dos empreendedores de sucesso

\begin{tabular}{|l|l|}
\hline \multicolumn{1}{|c|}{ CARACTERÍSTICAS } & \multicolumn{1}{c|}{ DESCRIÇÃO } \\
\hline Diferencia-se das outras pessoas & $\begin{array}{l}\text { Através de atitudes pró ativas e de seu pensamento inovador, } \\
\text { conseguem se destacar em meio a todos. }\end{array}$ \\
\hline Raciocínio rápido & Tomam decisões imediatas e com facilidade. \\
\hline Espírito inovador & Conseguem fazer coisas de formas inusitadas. \\
\hline Visionário & Conseguem enxergar as oportunidades em ambientes comuns \\
\hline Dinâmico & Tem energia e atitude diante das atividades cotidianas \\
\hline Busca constante por atualização & $\begin{array}{l}\text { Eles entendem que quanto mais informados e atualizados, mais } \\
\text { chances terão de obter sucesso. }\end{array}$ \\
\hline Organização & $\begin{array}{l}\text { Entendem que para serem mais produtivos e ter pensamentos } \\
\text { mais claros, precisam ser organizados. }\end{array}$ \\
\hline Satisfação na atividade escolhida & $\begin{array}{l}\text { Por gostarem do que fazem, se dedicam cada vez mais e } \\
\text { passam o tempo que for necessário. }\end{array}$ \\
\hline Persistentes & $\begin{array}{l}\text { Quando o objetivo almejado não é conquistado, buscam } \\
\text { alcança-lo experimentando outros métodos. }\end{array}$ \\
\hline Determinados & Sabem onde querem chegar. \\
\hline Assumem riscos calculáveis & $\begin{array}{l}\text { Não se arriscam aleatoriamente, mas buscam informações e se } \\
\text { preparam para a empreitada. }\end{array}$ \\
\hline $\begin{array}{l}\text { Tem objetivos profissionais e pessoais a a } \\
\text { longo prazo }\end{array}$ & $\begin{array}{l}\text { Buscam construir de forma distinta o seu futuro, com planos } \\
\text { de riqueza a longo prazo }\end{array}$ \\
\hline Líder & $\begin{array}{l}\text { Sabem convencer outras pessoas de suas ideias e fazer com que } \\
\text { elas o sigam. }\end{array}$ \\
\hline
\end{tabular}

Fonte: Adaptado de Dornelas (2008)

Mendes (2016) ainda destaca que está na essência desse indivíduo e na forma de distinguir, e transformar dificuldades em oportunidade de novos negócios e que empreender é muito mais que lucratividade, é colaborar para uma comunidade para ser reconhecido, e que o verdadeiro empreendedor modifica todo o cenário econômico entusiasmado em colaborar e inovar.

Diante da mudança do mercado de trabalho no início deste século, os indivíduos foram induzidos a saírem da "zona de conforto", onde no século passado a maior parte dos empregos era formal, contrapondo-se ao atual, donde inicia-se a reestruturação das empresas, ampla concorrência e a busca constante do conhecimento (BIZZOTTO, 2008).

Estudos mostram que, devido a estabilização econômica e a globalização, o mercado brasileiro vem tomando medidas para se tornar cada vez mais competitivo e atraente. Apesar da maior parte das micros e pequenas empresas são criadas por gestores que atuam de forma empírica na gestão, acarretando uma mortalidade das empresas em cerca de 50\% nos anos iniciais (DORNELAS, 2016).

Após uma pesquisa comparativa, feita com 2000 mil empresas ativas e inativas, constatou-se que $84 \%$ das empresas inativas não souberam aperfeiçoar sistemicamente os produtos e serviços aos clientes, e 64\% não tinham experiência ou conhecimento no ramo para abertura da empresa, sendo que houve uma falta de planejamento a longo prazo para abertura. (SEBRAE, 2016), mostrando que estar 
atento às inovações, bem como estar atento às mudanças de comportamento do consumidor é importantíssimo para manter uma empresa em funcionamento. Destarte, observa-se o fenômeno das novas economias, como a Economia Compartilhada, Economia Colaborativa e, complemento deste estudo, a Economia Criativa.

\section{Economia Criativa}

Economia é o meio de distribuição e aproveitamento de recursos escassos, com a finalidade de satisfazer as necessidades das pessoas, também conhecida como ciência social, onde tem o propósito de igualar as fontes produtivas limitadas com as necessidades humanas ilimitadas (VASCONCELLOS, 2008). Diante dessa análise e das novas tendências mercadológicas surge a economia criativa, onde é a junção de recursos culturais e intelectuais, no qual juntamente com a criatividade e inovação geram oportunidades de negócio (SEBRAE, 2018).

Em contrapartida estudos sintetizam que economia criativa não somente é a junção desses três recursos, mas também com bastante foco na sustentabilidade, possibilitando uma forte expansão econômica (CHEDID, 2017).

Dentro da Economia Criativa, existem divisões.

Parodi (2018) diz que "Encaixam-se dentro desse conceito setores e atividades com conhecimentos aplicados com criatividade e inovação como": Design, Moda, Arquitetura, Publicidade, Expressões culturais, Patrimônio e artes, Música, Artes cênicas, Editorial, Audiovisual, Tecnologia e Inovação, Biotecnologia e P\&D (produção e desenvolvimento).

Ressaltando que o produto gerado, além de ser criativo precisa ter um valor agregado, seja para o criador ou cliente (TECH, 2016).

Conforme a UNCTAD (2010) a Economia Criativa englobando produtos e lugares que tenham valores culturais e intangíveis, assim como todos os empregos que estejam ligados a esses negócios são considerados indústrias criativas.

No Brasil a participação da indústria criativa ainda prevalece baixa, com cerca de $2,5 \%$ do Produto Interno Bruto (PIB), comparado a expressividade dessa economia em outros países (CHEDID, 2017).

Estudos recentes mostram que a indústria criativa mobiliza 30 milhões de empregos em todo um mundo, ou seja, 2,25 bilhões de dólares anualmente, fora as exportações globais que chegam a contabilizar mais de 250 bilhões de dólares (UNESCO, 2018).

318 Id on Line Rev. Mult. Psic. V.12, N. 42, Supl. 1, p. 314-334, 2018 - ISSN 1981-1179 Edição eletrônica em http://idonline.emnuvens.com.br/id 
Com isso a grande tendência que essa economia possibilita é a troca de se "ter um bem material", pelo "compartilhamento de experiências" (GABRIELLE, 2017). No setor de cafés gourmets, a estimativa de crescimento é 18\% em 2018, ou seja, a previsão de vendas é 750 mil sacas (ABIC, 2018).

Neste contexto, observa-se o fortalecimento de uma demanda de produtos gourmets, bem como ambientes aprazíveis, onde o consumidor, mais do que comprar um determinado item, ele possa aprecialo.

\section{Cafeteria}

Segundo o ITPC (2014 apud SEBRAE, 2015) o ramo de cafeterias cresceu consideravelmente em 2014, com taxas de 8,02\%, faturando cerca de R 82,5 bilhões. Dados demonstrados no estudo indicam que o reajuste de preços em média no ramo de panificação foi de $11,5 \%$, devido às seguintes consequências: alta do salário, energia, aumento dos impostos, embalagens e custos não previstos (SEBRAE, 2015).

Estudos mais recentes mostram que o ramo de padarias e confeitarias cresceu 3,2\% em 2017, sem levar em consideração a inflação, chegando a faturar cerca de R \$ 90,3 bilhões (ABIP, 2015 apud ITPC, 2014).

Os resultados só não foram mais crescentes devido à concorrência acirrada, onde as mesmas buscam sempre inovar seja essa concorrência supermercados, atacarejos, empresas de congelados, franquias de pães, no qual disponibiliza o produto e equipamentos para o comerciante somente fazer o preparo final (ABIP, 2018).

No âmbito de geração de emprego, estudos feitos com cerca de 70 mil padarias apontam que em média existem 12 funcionários por organização. Concluído que no mínimo são 800 mil empregos diretos gerados em todo o país. De forma indireta são quase 1,8 milhões (ABIP, 2018).

Dentre todos os ramos de panificação, a mais adequada e lucrativa são as padarias tradicionais são oferecidos produtos e serviços mais do cotidiano, além de produtos complementares com refeição e produtos alimentícios. Nesse segmento de panificação o público alvo são indivíduos da classe A B e C. com participação de 76\% e não reconhecimento da marca de 3\% (SEBRAE, 2015).

Entretanto, um estudo feito por a ABIP(2014), onde fez seu planejamento estratégico para 10 anos, as tendências de padarias indica mudanças, onde o maior crescimento tende a ser para as padarias gourmet, se disponibiliza de um espaço maior, entre $100 \mathrm{~m} 2$ a $300 \mathrm{~m} 2$, dispondo de um ambiente mais aconchegante, e com uma ampla diversidade de produtos, que vai desde o café da manhã até caldos a 
noite, tem-se foco no foodservice, e oferece produtos como pães especiais, vinhos e até cafeteria. Podendo optar por fornecer produtos para outros estabelecimentos.

Os consumidores de cafés gourmet, buscam assim como os apreciadores de vinhos e outros produtos com qualidade diversificada, sempre buscam novidades, novos lançamentos, que promovem inovação ou até novas tendências em produto do café (SEBRAE, 2014).

No âmbito econômico, a produção de café em 2015, passou de 20.085 para 20.333 milhões de sacas por ano, onde cada saca contém $60 \mathrm{Kg}$ (EMBRAPA, 2015). Espera-se que para o ano de 2018 a produção cresça para 22,7 milhões de sacas, preferencialmente os produtos com certificado de qualidade e sustentabilidade (ABIC, 2017).

O mercado dos cafés destacou um aumento para o consumo de produtos no setor gourmet, como busca por cafeterias especializadas, dessa forma unindo o desejo de um café de qualidade aliado a um ambiente especializado, gerando uma oportunidade de negócio no setor (SEBRAE, 2014).

Estudos apontam que no Brasil, 95\% da população tem o costume de tomar café da manhã em estabelecimentos comerciais. Parte do estudo sintetiza a grande demanda por cafés especiais, com grãos mais refinados, feitos na hora e personalizados (SEBRAE, 2018).

Oliveira (2014) afirma que a sociedade tem passado por grandes mudanças e a avanços tecnológicos, e que trazem consigo novos hábitos de consumo, com informações de forma mais acessível, mostrando a evolução social e econômica, dando oportunidade para novas tendências no setor de alimentação como a grande demanda por cafeterias que agregam valor a busca incessante por produtos e bebida de alta qualidade as classes $C$ também está em busca de algum status, e não apenas as classes A e B.

O Relatório de Tendências do Mercado, Euromonitor (2017) afirma que entre os anos de 20162021 o café terá um crescimento no consumo que poderá chegar a 1,7 milhões de toneladas com uma média anual de 3,5\% nesse período. E que apesar da premiunrização está em expansão, o café tradicional é muito procurado por preços atrativos e ainda um fator determinante, apresentando algumas conclusões dessas novas tendências de cafés e cafeterias, afirmando que as principais peculiaridades valorizadas serão: Um ambiente agradável para conversar, a qualidade dos cafés, as diferentes formas de preparo, a diversidade de alimentos, sendo que algumas das razões para o cliente não voltar ao estabelecimento são: local com muito barulho, com pouco espaço, falta de qualidade do café e pouca variedade nos alimentos e qualidade na prestação do serviço, de forma acolhedora é visto como um diferencial nesses ambientes.

A Euromonitor (2017) enfatiza que para conquistar um maior número de frequentadores é importante aliar o consumo do café á ambientes de convívio social e profissional, agregando para os clientes conforto e um ambiente que favoreça a produtividade. Com a evolução do brasileiro, foi dividida 
em 4 ondas de transitação, e a que tem a maior tendência em crescimento é a 1 onda, que é a venda massiva do café, que com os avanços tecnológicos levam o café fresco até o alcance do cliente, com embalagens diversificadas a vácuo.

Desta forma, observa-se que o ramo de cafeterias está em pleno desenvolvimento.

\section{Método}

O estudo em questão caracterizou-se por ser de natureza básica, onde o objetivo é a geração de novos conhecimentos que será útil para os avanços científicos, Gerhardt e Silveira (2009) abordagem quantitativa, dada a perspectiva de Prodanov e Freitas (2013) que considera a quantificação dos dados coletados, para posterior classificação e análise. A partir do método survey, dados obtidos através da pesquisa de opinião de determinada população, utilizando o questionário como instrumento de coleta de dados (FONSECA,2002), analisada por meio da estatística descritiva que Prodanov e Freitas (2013) afirma que busca identificar a frequência que ocorre os episódios, buscando as causas e a natureza.

A amostra utilizada partiu da população de 7.513 que representa $15,5 \%$ dos habitantes que possuem renda igual ou superior a dois salários mínimos da cidade de Brejo Santo, cuja amostra ideal foi 130 indivíduos, possui, dado esse alcançado por meio da fórmula do cálculo amostral, onde se considerou $95 \%$ de confiabilidade e 5\% de erro. Foram incluídos na pesquisa indivíduos da cidade pesquisada e de cidades vizinhas.

$$
n=\frac{N \cdot Z^{2} \cdot p \cdot(1-p)}{Z^{2} \cdot p \cdot(1-p)+e^{2} \cdot(N-1)}
$$

Onde:

n - amostra calculada $\mathrm{N}$ - população $\mathrm{Z}$ - variável normal padronizada associada ao nível de confiança - verdadeira probabilidade do evento e - erro amostral

O instrumento de coleta de dados foi um questionário online, por meio da plataforma Google forms, encaminhado por e-mails e grupos de whatsapp, contendo 16 perguntas estruturadas e fechadas.

\section{Resultados e Discussões}

A coleta dos dados foi realizada através de questionários e aplicada por meio do Google forms com perguntas objetivas, num total de 130 pessoas que frequentam a cidade de Brejo Santo-CE, onde 
os participantes responderam perguntas sobre os alimentos que costumam consumir diariamente, a frequência que se consome o café, e o conhecimento acerca dos cafés especiais, e se há demanda por ambientes que ofereçam qualidade nos produtos e serviços.

\section{Gráfico 1:Gênero}

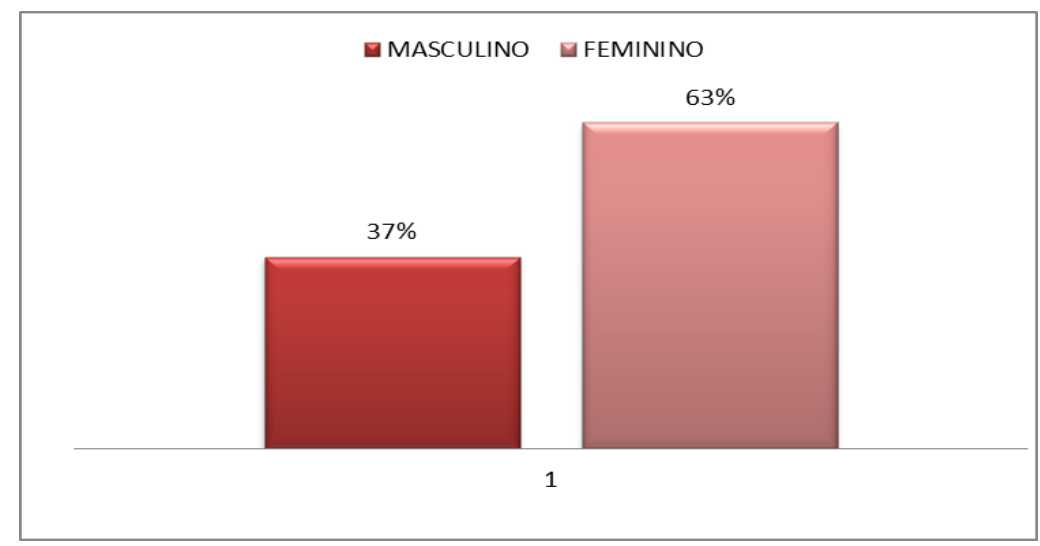

Fonte: Dados da pesquisa (2018).

O gráfico representa que de acordo com a amostra grande parte dos possíveis clientes da cafeteria seria do sexo feminino representando $63 \%$ das pessoas e apenas $37 \%$ corresponde aos indivíduos do sexo masculino, representando uma diferença de quase $50 \%$. O resultado pode ser dar devido ao fato de que existem muito mais lugares de entretenimento para o público masculino, acompanhado ou não, do que para o feminino, considerando todo um perfil de mulheres de cidades pequenas. Os dados apresentados podem também ser utilizados tanto para a decisão da decoração do local, bem como entender quais serão os canais de divulgação do mesmo.

Gráfico 2: Faixa etária

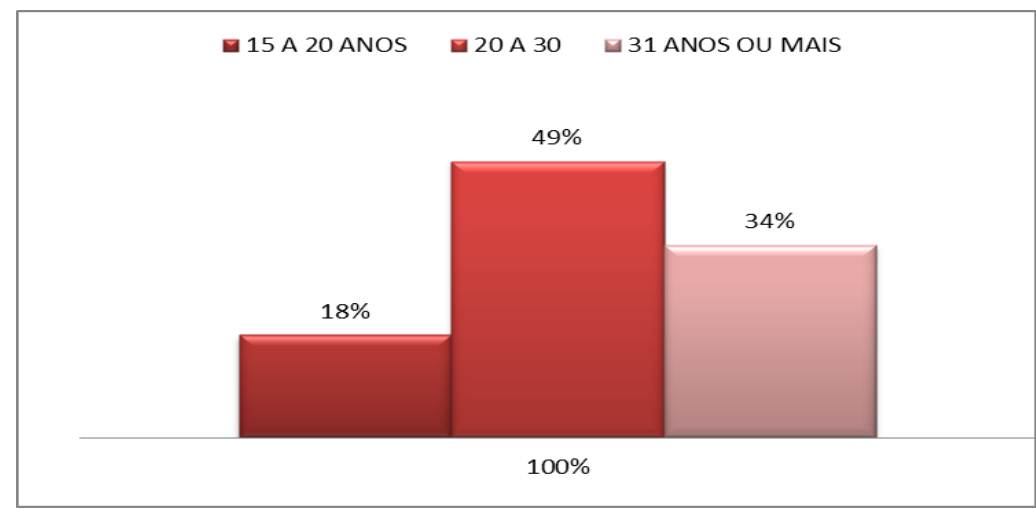

Fonte: dados da pesquisa (2018). 
Após a análise do gráfico 2, observa-se que o público alvo estaria em pessoas na faixa-etária que compreende 20 a 30 anos, lembrando que pessoas com mais de 31 anos seguem logo depois. Ao observar-se empiricamente os tipos de entretenimentos ofertados na cidade, observa-se que ambientes que contemplem essas pessoas, é quase inexistente.

Gráfico 3:Alimentos consumidos diariamente

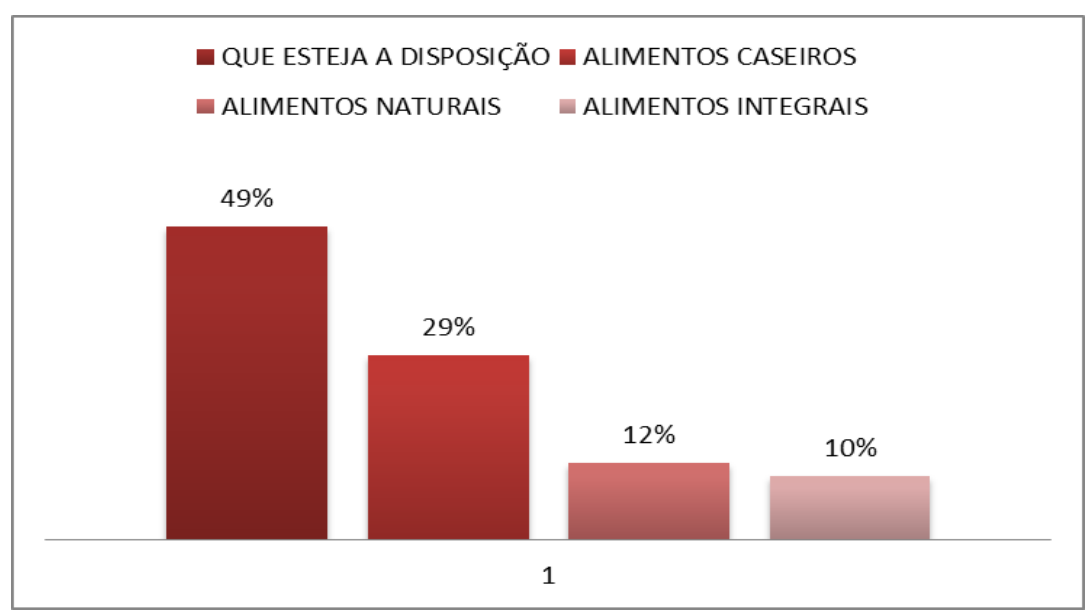

Fonte: dados da pesquisa (2018).

O gráfico 3 mostra que $49 \%$ se alimentam daquilo que estiver à disposição, podendo ser traduzido que aquilo que não é ofertado, não é consumido. Seguindo a linha atual de qualidade de vida, encontramos $29 \%$ dos respondentes que dão preferência a produtos caseiros. Como itens crescentes, obteve-se $22 \%$ entre alimentos naturais e integrais, o que segundo o SEBRAE (2017), tem-se uma tendência de crescimento no setor de alimentos naturais e uma valorização nos alimentos regionais. Entretanto apenas $12 \%$ representando a população que se alimenta de alimentos integrais.

Os dados do gráfico 4 , na sequência, relatam que dentre os resultados coletados, $62 \%$ das pessoas optam por consumir lanches frescos e naturais como foi descrito no gráfico anterior. Tendo em vista as tendências dos consumidores, cujo procuram um mercado no qual ofereça produtos gourmet, com o intuito de apreciar produtos inovadores, qualidade diversificada e novas tendências e cafés especiais (SEBRAE, 2014). 
Gráfico 4: Desejo de consumir um pão quente e demais acompanhamentos do café matinal.

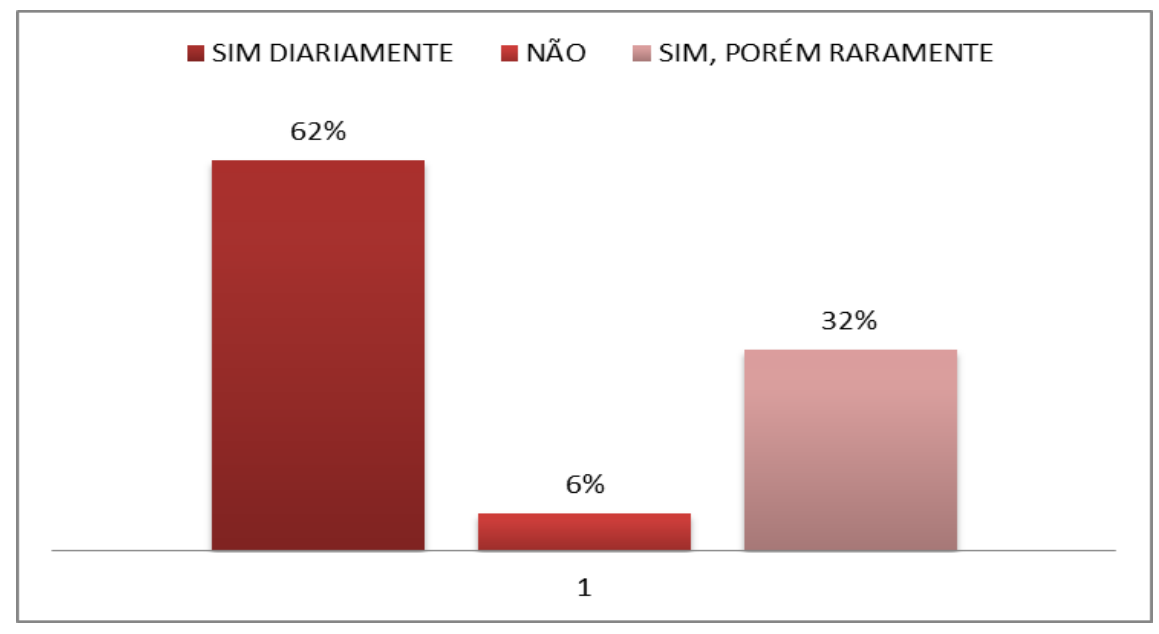

Fonte: dados da pesquisa (2018).

Gráfico 5: Aceitaria pagar pelo serviço de entrega de pães e outros alimentos.

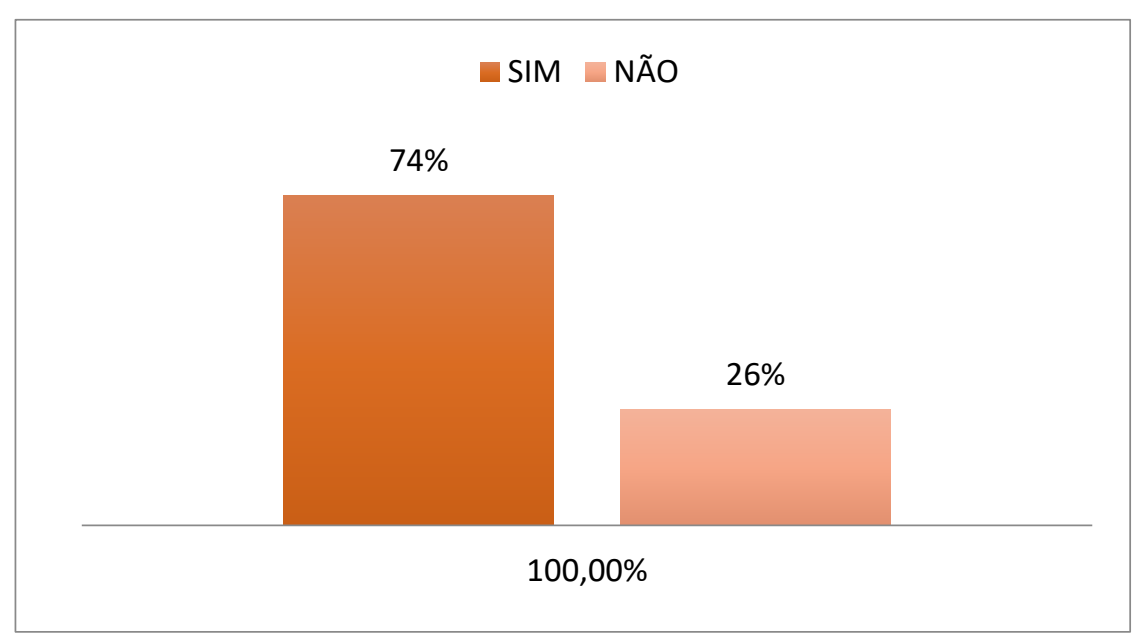

Fonte: dados da pesquisa (2018).

De acordo com os dados coletados e a busca por praticidade por parte dos clientes (gráfico 5), $74 \%$ dos entrevistados pagariam mensalmente por serviços de entrega de pães e outrosalimentos da cafeteria, tendo em vista que $26 \%$ não optariam por esse serviço, demonstrando assim, a necessidade do consumidor de conforto e agilidade. 
Gráfico 6: Quanto pagaria pelo serviço de delivery de pães e complementos?

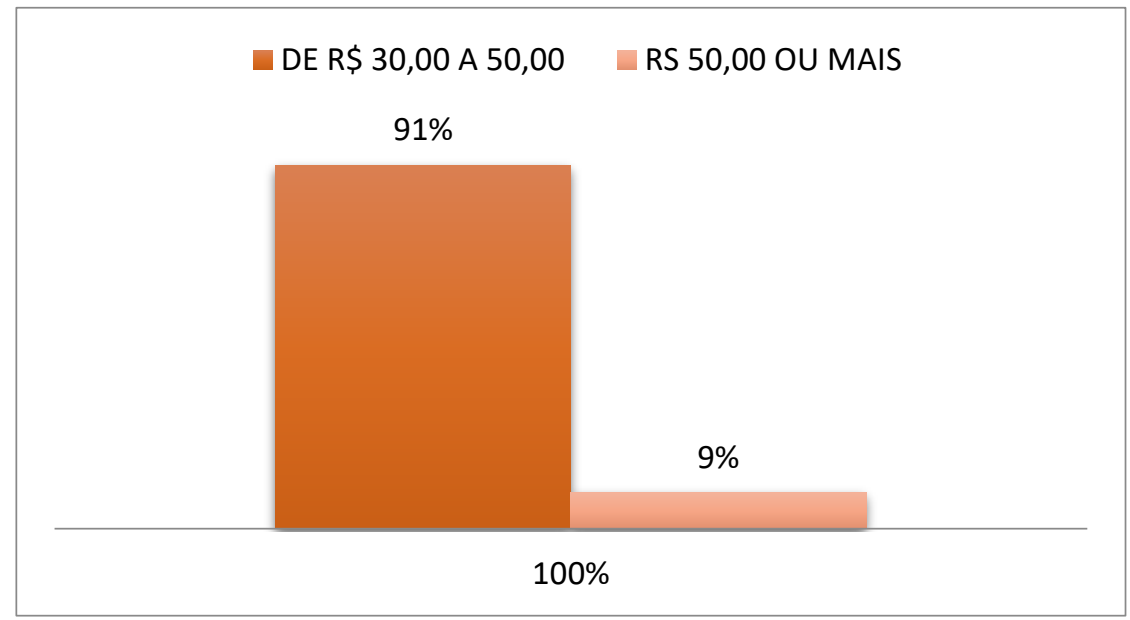

Fonte: dados da pesquisa (2018).

Considerando a análise do gráfico anterior, dos $74 \%$ dos futuros clientes dispostos a pagar mensalmente pelo serviço ofertado, $90 \%$ dessa população está disposta a pagar de $\mathrm{R} \$ 30,00$ a $\mathrm{R} \$ 50,00$ por mês, o que seria uma média de R - 1,15 a R \$ 1,50 adicional por entrega. Tal valor é exequível, já que a cidade é pequena e poderia utilizar-se de bicicletas para a entrega.

Gráfico 7: Que tipo de serviço seria preferível, no tocante ao consumo de pães, mesmo tendo tempo livre.

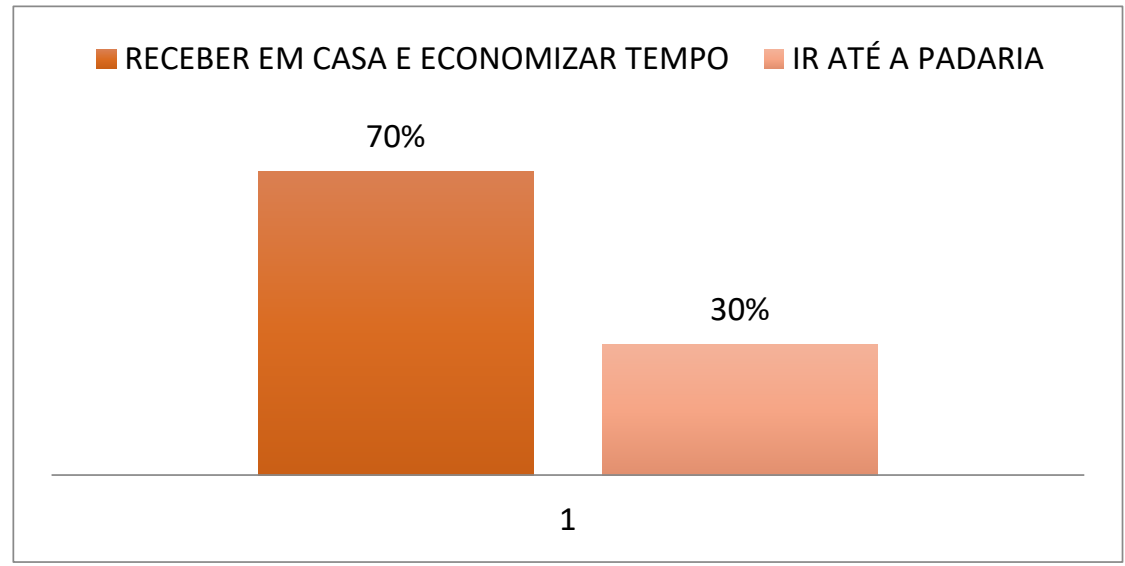

Fonte: dados da pesquisa (2018).

Pesquisas apontam que 95\% da população prefere tomar café da manhã em estabelecimentos comerciais (SEBRAE, 2018). Em contrapartida, diante da população abordada e devido à praticidade 
exigida pelas pessoas, como já foi abordado em analises anteriores, $70 \%$ prefere consumir os produtos em casa para poupar tempo, onde apenas $30 \%$ optam por ir à padaria.

Gráfico 8: Consumo diário de café

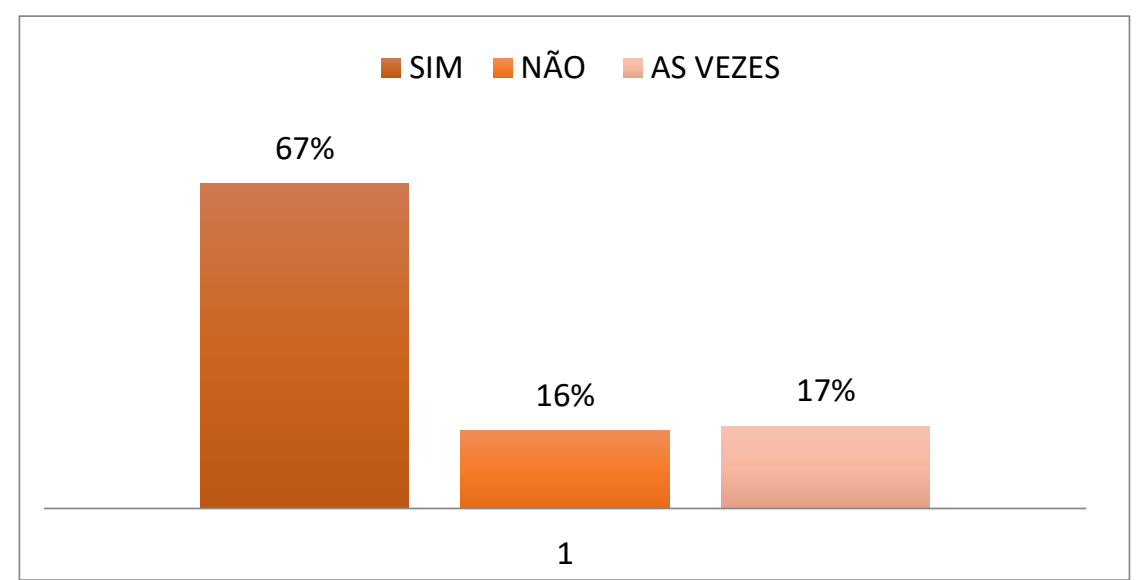

Fonte: dados da pesquisa (2018).

O Relatório de Tendências do Mercado (2017)relata que entre os anos de 2016 - 2021 o consumo de café poderá aumentar a 1,7 milhões de toneladas com uma média anual de 3,5\% nesse período. Diante desse cenário $67 \%$ dos entrevistados costumam beber café, em comparação a $17 \%$ no qual responderam que as vezes ingerem a bebida e $16 \%$ no qual não consomem a bebida de maneira alguma.

Gráfico 9: Onde prefere tomar café

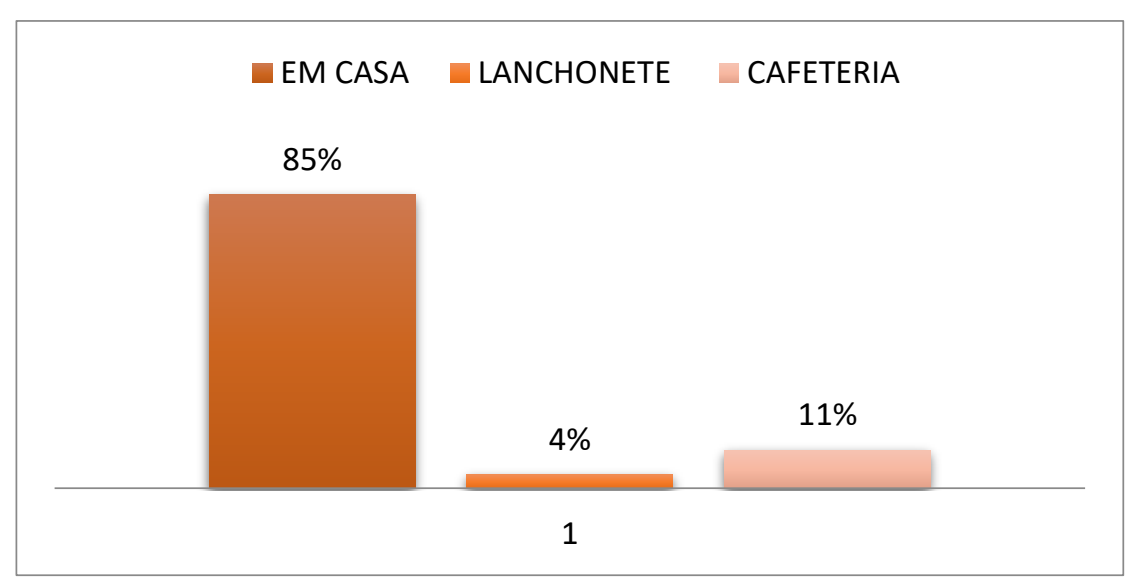

Fonte: dados da pesquisa (2018). 
Estudo feito pelo mesmo relatório entre os anos de 2016- 2021 afirmam que as principais peculiaridades valorizadas pelo cliente são: qualidade do café, variedade dos alimentos, ambiente confortável para socializar, ambientalização do ambiente no qual é visto como fator diferencial de competitividade, corroborando com as respostas da pesquisa.

Gráfico 10: Conhecimento do café gourmet

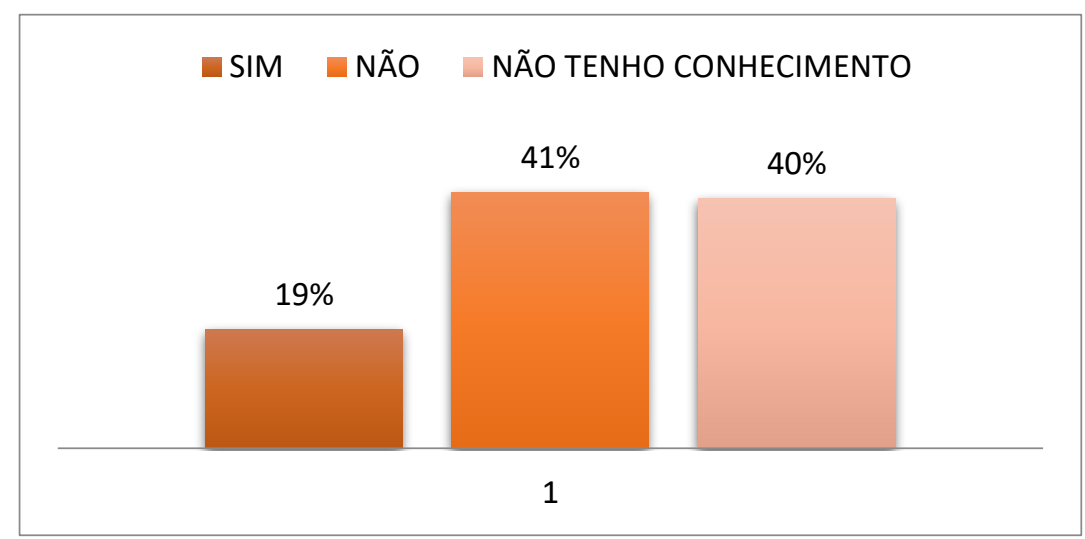

Fonte: dados da pesquisa (2018).

O setor gourmet de cafés destacou um aumento considerável no ramo, consumidores desse ramo buscam constantemente cafeterias especializadas, desejando um café de alta qualidade e um ambiente especializado, onde surgem novas oportunidades de negócios nesse ramo (SEBRAE, 2014). Dentro do cenário abordado $41 \%$ da amostra preferem ou tomam essa especialidade de café, acirrada a $40 \%$ que não tem conhecimento dessa especialidade e $19 \%$ não toma e nem prefere cafés gourmets. Vale ressaltar que os consumidores de cafés gourmets gostam de produtos que tenham qualidade diversificada, alto teor de inovação, lançamentos constantes de novos produtos/serviços (SEBRAE, 2014).

Gráfico 11: Ambiente da cafeteria.

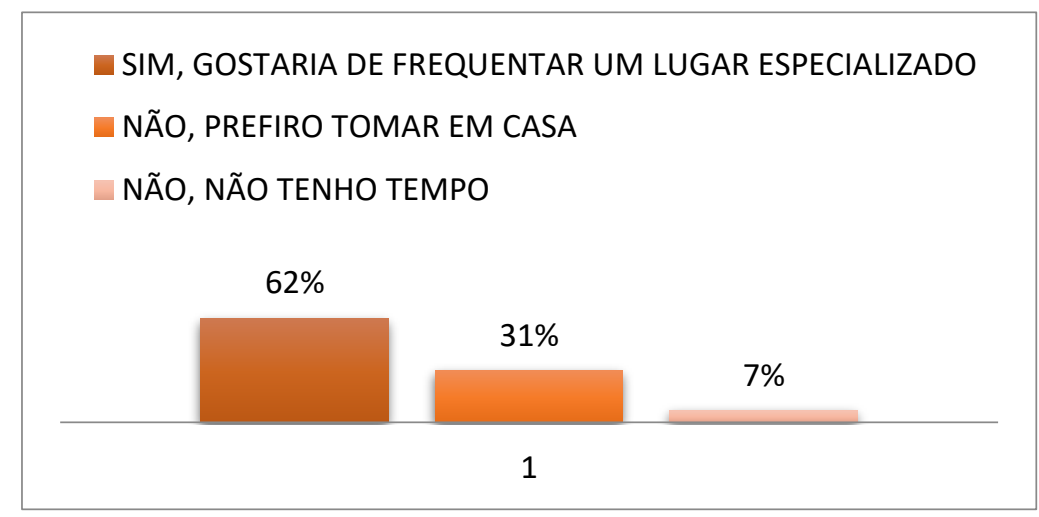

Fonte: dados da pesquisa (2018). 
Diante da necessidade de novas tendências no qual a sociedade vem buscando aliados as mudanças tecnológicas, outras formas e hábitos de consumo ver surgindo. O século XXI é considerado a era da informação mostrando a evolução social e econômica, onde abre-se oportunidades para empreender nessas novas tendências, principalmente no setor alimentício, como por exemplo a grande demanda por cafeterias que ofereçam bebidas de alta qualidade (OLIVEIRA, 2014). Com 62\% do público abordado, gostariam de frequentar um ambiente especializado em café, com uma boa ambientaliazação. Tendo em vista $31 \%$ preferem a praticidade tomando em casa, em relação a $6 \%$ que não tem tempo para apreciar os produtos oferecidos pelas cafeterias.

Gráfico 12: Frequência semanal a uma cafeteria

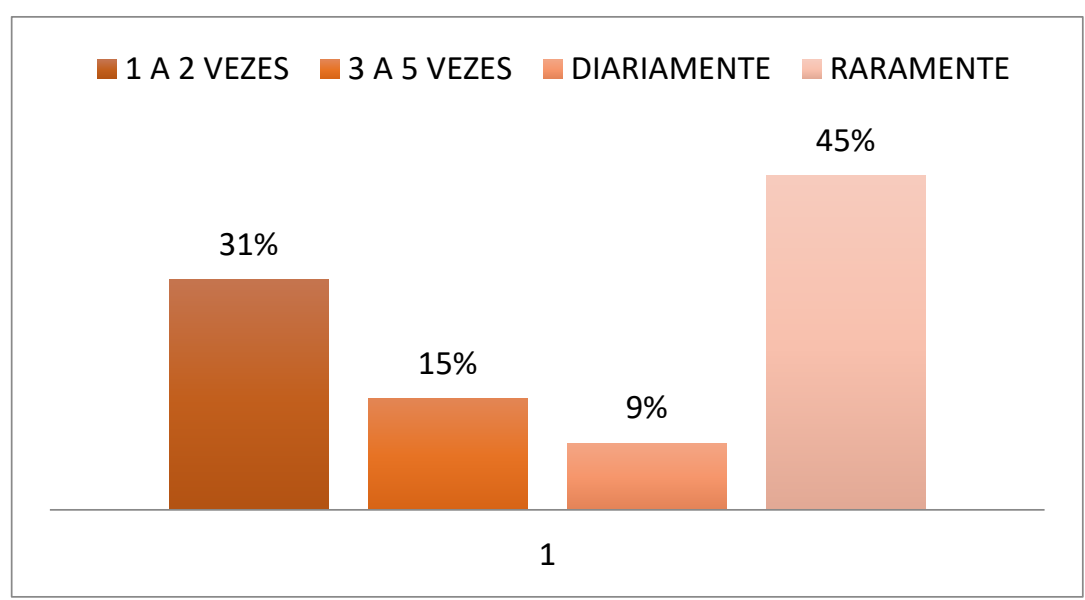

Fonte: dados da pesquisa (2018).

Observa-se que haveria clientela para a cafeteria, já que em torno de 40 pessoas frequentariam uma cafeteria 1 a 2 vezes por semana e uma média de 19 pessoas frequentaria 3 a 5 vezes. $O$ fato de obter-se na pesquisa que $45 \%$ não frequentariam pode ser ao entender que os outros respondentes - 55\% frequentariam o local, sem falar que, geralmente, o cliente vai acompanhado ou para encontrar amigos. 
Gráfico 13: Motivos para frequentar uma cafeteria

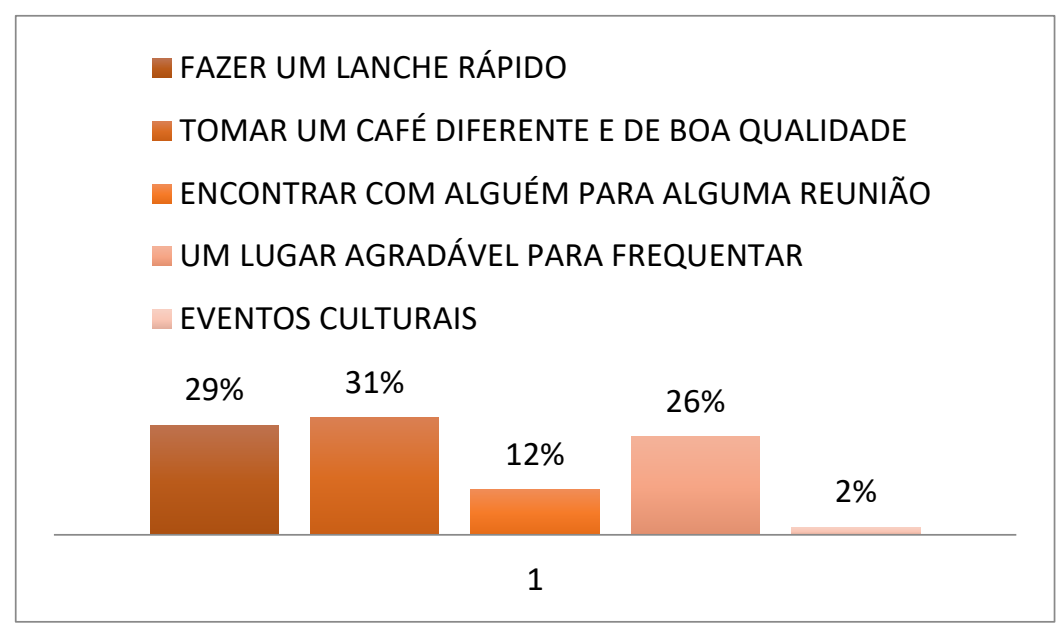

Fonte: dados da pesquisa (2018).

Observa-se que $31 \%$ busca consumir produtos diferentes e de qualidade, enquanto que $12 \%$ buscam um local para fazer reuniões e $26 \%$ iria pelo local, o que perfaz $38 \%$ de pessoas que buscam um ambiente agradável.

Gráfico 14: Preferência de horários

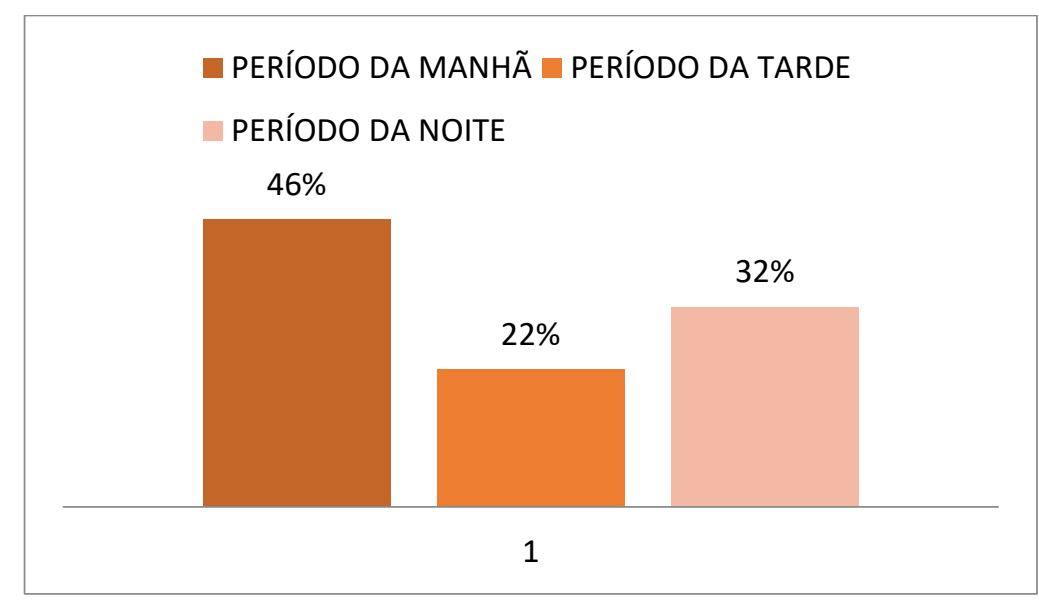

Fonte: dados da pesquisa (2018).

Por se tratar de café, $46 \%$ dão preferência ao horário matutino, no entanto $32 \%$ não optaram por o período noturno, $22 \%$ a tarde, dessa forma, observa-se que a Cafeteria teria clientes em todos os horários, sendo necessário adequar os cardápios. 
Gráfico 15: Fatos que impulsionam a frequência do consumido

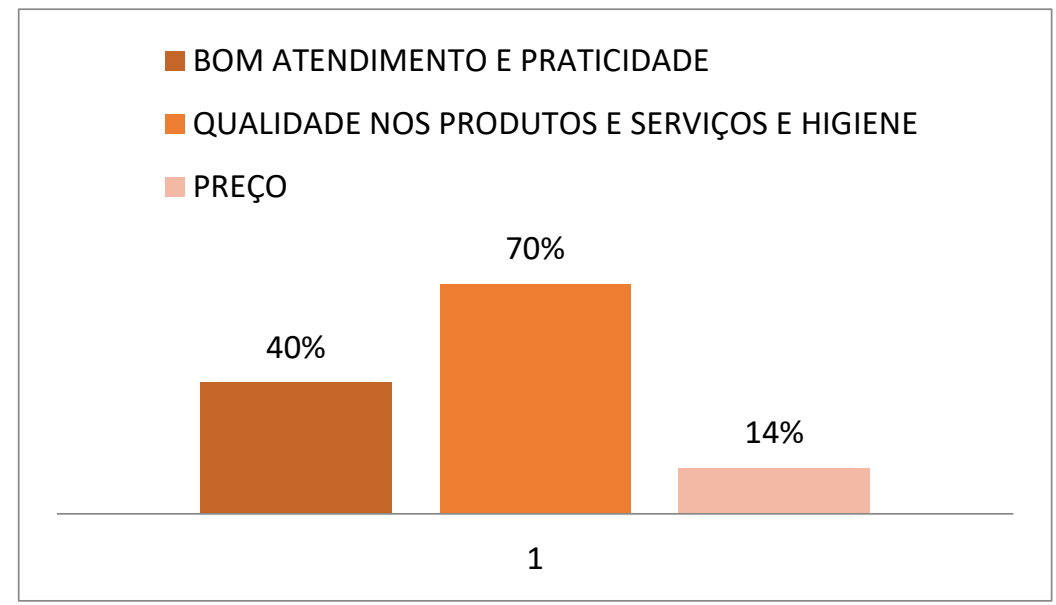

Fonte: dados da pesquisa (2018).

Como os itens eram de múltipla escolha, obteve-se um percentual maior que $100 \%$, sendo que $70 \%$ se dizem atraídos pela higiene e qualidade dos produtos, sendo que apenas $14 \%$ estaria buscando preços acessíveis.

Gráfico 16: Consumir produto de preço mais elevado devido à qualidade

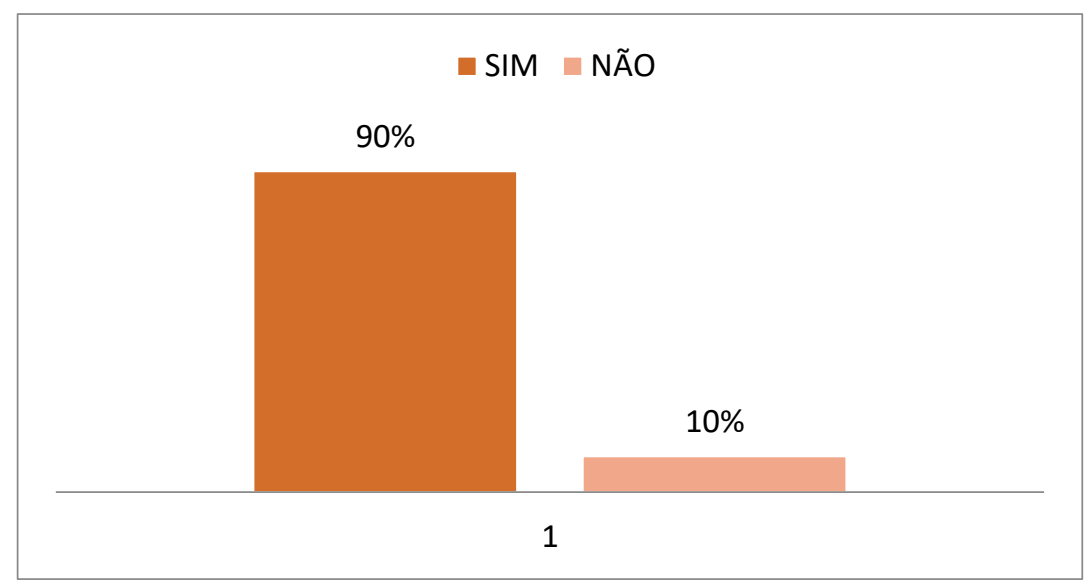

Fonte: dados da pesquisa (2018).

Corroborando com os gráficos 13 e 15 , os entrevistados afirmam que pagariam mais por produtos de melhor qualidade. 


\section{Considerações Gerais}

A economia criativa tem ganhado espaço no mercado, com ênfase em produtos que ofereçam algum diferencial. Os consumidores estão mais seletivos a cada dia e buscando produtos e serviços que contenha algum valor agregado, principalmente de forma sustentável e que ofereçam qualidade, inovação e quanto aos locais busca-se um ambiente agradável que venha a beneficiar a sua produtividade.

A pesquisa teve como objetivo principal identificar o interesse da população de Brejo Santo CE acerca da frequência e consumo em cafeteria gourmet na cidade, relacionando com a pergunta sobre o ambiente de cafeteria, onde $62 \%$ dos pesquisados afirmou que gostaria de um local especializado para frequentar, no qual o maior fator que influencia para dirigir-se ao estabelecimento é o bom atendimento e a praticidade que representa $70 \%$ dos entrevistado, tendo em vista que a questão era de múltipla escolha e que os resultados poderiam superar os $100 \%$.

No entanto, alguns fatores foram identificados como desvantagens como o conhecimento dos pesquisadores sobre cafés especiais, que representa um percentual de $40 \%$.

A pesquisa demonstrou resultados significativos de uma parcela de pessoas que procuram por lugares com ambiente agradável, sejam ele para uma reunião corporativa, pessoal ou apenas para provar de uma bebida que ofereça um diferencial e inovação no produto.

Nesse estudo os objetivos foram alcançados, de forma explicita mostrando que os principais motivos que levam os consumidores a frequentar o ambiente de cafeteria gourmet é a qualidade do local, o atendimento e que $90 \%$ dos entrevistados preferem pagar mais caro por algo que lhe ofereça confiabilidade, e que o preço não é fator determinante de compra.

Por meio da coleta de dados foi possível compreender a percepção e a adesão dos entrevistados a uma cafeteria gourmet na cidade de Brejo Santo-CE, evidenciando uma demanda por lugares inovadores e que ofereçam confiança para com o consumidor. Frente a esse contexto, percebe-se a necessidade de pesquisas que envolvam um contato específico com a demanda que se apresenta como um público em potencial para abertura de empreendimento, adentrando características e particularidades que favoreçam o desenho do cenário para as novas tendências de economia e ambientes gourmet. 


\section{Referências}

ALMEIDA, Martinho Isnard Ribeiro de. Manual do planejamento estratégico: desenvolvimento de um plano estratégico com a utilização de planilhas Excel. 3 ed. -São Paulo: Atlas,2010.

ASSOCIAÇÃO BRASILEIRA DA INDÚSTRIA DO CAFÉ. Mercado de cafés especiais deve crescer 19\% em 2018. Disponível em :<http://abic.com.br/mercado-de-cafes-especiais-deve-crescer-19-em2018/>. Acessado em:23 out. 2018.

\section{ASSOCIAÇÃO BRASILEIRA DA INDÚSTRIA DE PANIFICAÇÃO E CONFEITARIA.Visão do Setor de Panificação e Confeitaria do Futuro \\ .Disponível em: $\quad$ http://www.abip.org.br/site/visao-do-setor-de-panificacao-e-confeitaria-para-o- futuro/>Acesso em: 15 out. 2018.}

Balanço e Tendências do Mercado de Panificação e Confeitaria. 2018.Disponível em: http://www.abip.org.br/site/wp-content/uploads/2018/03/INDICADORES-E-TENDENCIAS-DEMERCADO.pdf>. Acesso em: 15 out. 2018.

BIZZOTTO, Carlos Eduardo Negrão. Plano de negócios para empreendimentos inovadores. 1 ed. São Paulo: Atlas, 2008.

CHEDID. https://www.politize.com.br/economia-criativa/Acesso: 15 out.2018.

CHIAVENATO, Idalberto. Empreendedorismo: dando asas ao espírito empreendedor. 4 ed.- Barueri, SP: Manoele, 2012.

Como o Sebrae atua no segmento de Economia Criativa. Disponível em: http://www.sebrae.com.br/sites/PortalSebrae/segmentos/economia_criativa/como-o-sebrae-atua-nosegmento-de-economia-criativa,47e0523726a3c510VgnVCM1000004c00210aRCRD. Acesso em: 01 Nov.2018.

DORNELAS, José. Empreendedorismo: transformando ideias em negócios.6 ed. -São Paulo: Atlas,2016.

EMBRAPA - Empresa Brasileira de Pesquisa Agropecuária - Café é a Segunda Bebida Mais Consumida no Brasil. Site Disponível em: <https://www.embrapa.br/busca-de-noticias//noticia/2574254/cafe-e-a-segunda-bebida-mais-consumida-no-brasil>. Acesso em: 20 ago.2018.

FONSECA,J.J.J.D.Metodologia da pesquisa científica.Apostila(Apostila de Disciplina)- Universidade Estadual do Ceará.Fortaleza.2002.

GABRIELLE, Camila. A economia Criativa e suas perspectivas no Brasil. 2017. Disponível em: $<$ http://www2.faac.unesp.br/pesquisa/lecotec/projetos/oicriativas/index.php/2017/08/06/a-economiacriativa-e-suas-perspectivas-no-brasil/>. Acesso em: 01 nov. 2018.

GRACIOSO, Francisco. Marketing estratégico: Planejamento estratégico orientado para o mercado. 6 ed. 3 reimpr. -São Paulo: Atlas,2010. 
HISRICH,, Robert D.; PETERS,, Michael P.; SHEPHERD, Dean A. Empreendedorismo. 9. ed. Porto Alegre: AMGH,, 2014. 438 p.

Indicadores da Indústria de Café,2017. Disponível em: <http://abic.com.br/estatisticas/indicadores-da-industria/indicadores-da-industria-de-cafe2017/>Acesso em: 20 out. 2018.

MENDES, Jerônimo. Empreendedorismo 360: a prática na prática. - 3. ed. - São Paulo: Atlas, 2017. Métodos de pesquisa / [organizado por] Tatiana EngelGerhardt e Denise TolfoSilveira ; coordenado pela Universidade Aberta do Brasil - UAB/UFRGS e pelo Curso de Graduação Tecnológica - Planejamento e Gestão para o Desenvolvimento Rural da SEAD/UFRGS. - Porto Alegre: Editora da UFRGS, 2009.

OLIVEIRA, José Batista de. Visão do setor de panificação e confeitaria para o futuro. 2014. Disponível em: <http://www.abip.org.br/site/visao-do-setor-de-panificacao-e-confeitaria-para-ofuturo/>. Acesso em: 15 out. 2018.

Organização das Nações Unidas para a Educação, a Ciência e a Cultura Disponível em: $<$ https://nacoesunidas.org/unesco-lanca-em-sp-relatorio-global-sobre-economia-criativa-e-politicasculturais/> Acessado em: 10 out. 2018.

PARODI, Aline Machado. Guarda-chuva da criatividade econômica. Folha de Londrina. 09 de maio de 2018. https://www.folhadelondrina.com.br/economia/guarda-chuva-da-criatividade-economica1006267.html> Acesso em:01 nov. 2019.

REVISTA ÉPOCA. Título da matéria. Disponível em: $<$ https://epocanegocios.globo.com/Empreendedorismo/noticia/2018/04/5-tendencias-da-novaeconomia-para-empreendedores.html.>Acessado em: 20 out. 2018.

REVISTAISTOÉ. Cresce número de jovens empreendedores no Brasil. 2018. Disponível em: $<$ https://istoe.com.br/cresce-numero-de-jovens-empreendedores-no-brasil/>. Acesso em: 01 nov. 2018.

PRODANOV, C. C.; FREITAS, E. C. D.Metodologia do trabalho científico: Métodos e Técnicas da Pesquisa e do Trabalho Acadêmico. $2^{\mathrm{a}}$. ed. Novo Hamburgo: Universidade Freevale, 2013.

SALIM, Cesar Simões; SILVA, Nelson Caldas. Introdução ao empreendedorismo: construindo uma atitude empreendedora. Rio de Janeiro: Elsevier, 2010.

SANTOS, Glauber Eduardo de Oliveira. Cálculo amostral: calculadora on-line. Disponível em: <http://www.calculoamostral.vai.la>. Acesso em: 15 set. 2018.

SEBRAE. Projeto de desenvolvimento do setor de panificação com Atuação na Qualidade, Produtividade e Sustentabilidade. Disponível em:<https://bibliotecas.sebrae.com.br/chronus/ARQUIVOS_CHRONUS/bds/bds.nsf/bfd83326f9c69ef c659b57311b54c540/\$File/5960.pdf>. Acesso em: 10 jun. 2018.

SEBRAE. Como o Sebrae atua no segmento de Economia Criativa. Disponível em: <http://www.sebrae.com.br/sites/PortalSebrae/segmentos/economia_criativa/como-o-sebrae-atua-nosegmento-de-economia-criativa,47e0523726a3c510VgnVCM1000004c00210aRCRD> Acesso em: 25 Outubro 2018. 
TECH, Samba. O que é essa tal de Economia Criativa?. 2016. Disponível em: $<$ https://meusucesso.com/artigos/empreendedorismo/o-que-e-essa-tal-de-economia-criativa-1406/>. Acesso em: 01 nov. 2018.

TENDÊNCIAS DO MERCADO DE CAFÉ. Disponível em<http://consorciopesquisacafe.com.br/arquivos/consorcio/consumo/tendencias_do_mercado_cafe_2 017.pdf. Acesso em: out 2018.,

UNCTAD - UNITED NATIONS CONFERENCE ON TRADE AND DEVELOPMENT, Creative economy report 2010. Creativeeconomy: a feasibledevelopmentoption. U.N., 2010

Disponível em:>http://www.unctad.org/creative-economy> Acesso em: 15 out. 2018.

$$
\text { Novidades nas Cafeterias. Disponível em: }
$$

<http://www.sebraemercados.com.br/novidades-nas-cafeterias〉. Acesso em: 25ago.2018.

—. Como Elaborar um Plano de Negócios. Disponível
em:<http://www.bibliotecas.sebrae.com.br/chronus/ARQUIVOS_CHRONUS/bds/bds.nsf/5f6dba19ba af17a98b4763d4327bfb6c/\$File/2021.pdf. Acesso em: 15 out.2018.

Sobrevivência das Empresas no Brasil. Disponível em: $\overline{<\mathrm{https} / / / \mathrm{m}}$.sebrae.com.br/Sebrae/Portal\%20Sebrae/Anexos/sobrevivencia-das-empresas-no-brasil102016.pdf. Acesso em: 3 out. 2018

Mercado de Cafeteria. Disponível em<http://www.sebraemercados.com.br/wpcontent/uploads/2015/10/2014_06_26_BO_Maio_Turismo_Cafeteria_pdf.pdf.> Acesso em: 20 out. 2018.

\section{Como citar este artigo (Formato ABNT):}

TELES, Leticia Ricarte; FERREIRA, Thalia Lourdes; COSTA NETO, Manoel Leal; OLIVEIRA, Alyne Leite de; ALENCAR, Tharsis Cidália de Sá Barreto Diaz. Verificação de Interesse para a Implantação de uma Cafeteria na Cidade de Brejo Santo-CE. Id on Line Rev.Mult. Psic., 2018, vol.12, n.42, Supl. 1, p. 314-334. ISSN: 1981-1179.

Recebido: 06/11/2018;

Aceito: 07/11/2018 